\title{
A retrospective study of outcomes of radioiodine treatment for benign thyroid disease
}

\section{H Htun, DM Barton \\ Department of Diabetes and Endocrinology, Princess Royal Hospital, SaTH NHS Trust, West Midlands}

\section{Background}

- As radioiodine therapy is highly effective in curing Graves' hyperthyroidism and toxic multinodular goitre, the assessment of its efficacy by rendering those patients euthyroid, while avoiding the development of permanent hypothyroidism, is important.

\section{Aim}

- To determine the current practice of radioiodine treatment provided at our trust, in line with the recommended guidelines of the Royal College of Physicians.

- To compare our success rate with the published data.

\section{Method}

- Retrospective analysis of data from 100 hyperthyroid patients, who underwent radioiodine treatment during 2013 to 2017.

- Review of one year follow up clinical data, including RAl dose and thyroid function status, pre and post RAI treatment.

\section{Findings}

Demographic and biochemical

characteristics of the hyperthyroid patients underwent RA

\begin{tabular}{|c|c|}
\hline Characteristics & \\
\hline Mean age ( years) & $50(30-70)$ \\
\hline Male , $\mathbf{n}(\%)$ & 28 \\
\hline $\begin{array}{c}\text { Female }, \mathbf{n}(\%) \\
\text { Free T4 ( } \mathbf{n g} / \mathrm{dl}) \text { ), mean } \\
\text { (range) }\end{array}$ & 72 \\
\hline $\begin{array}{c}\text { TSH (mlU/L), mean }( \\
\text { range) }\end{array}$ & $25(10-154.8)$ \\
\hline
\end{tabular}

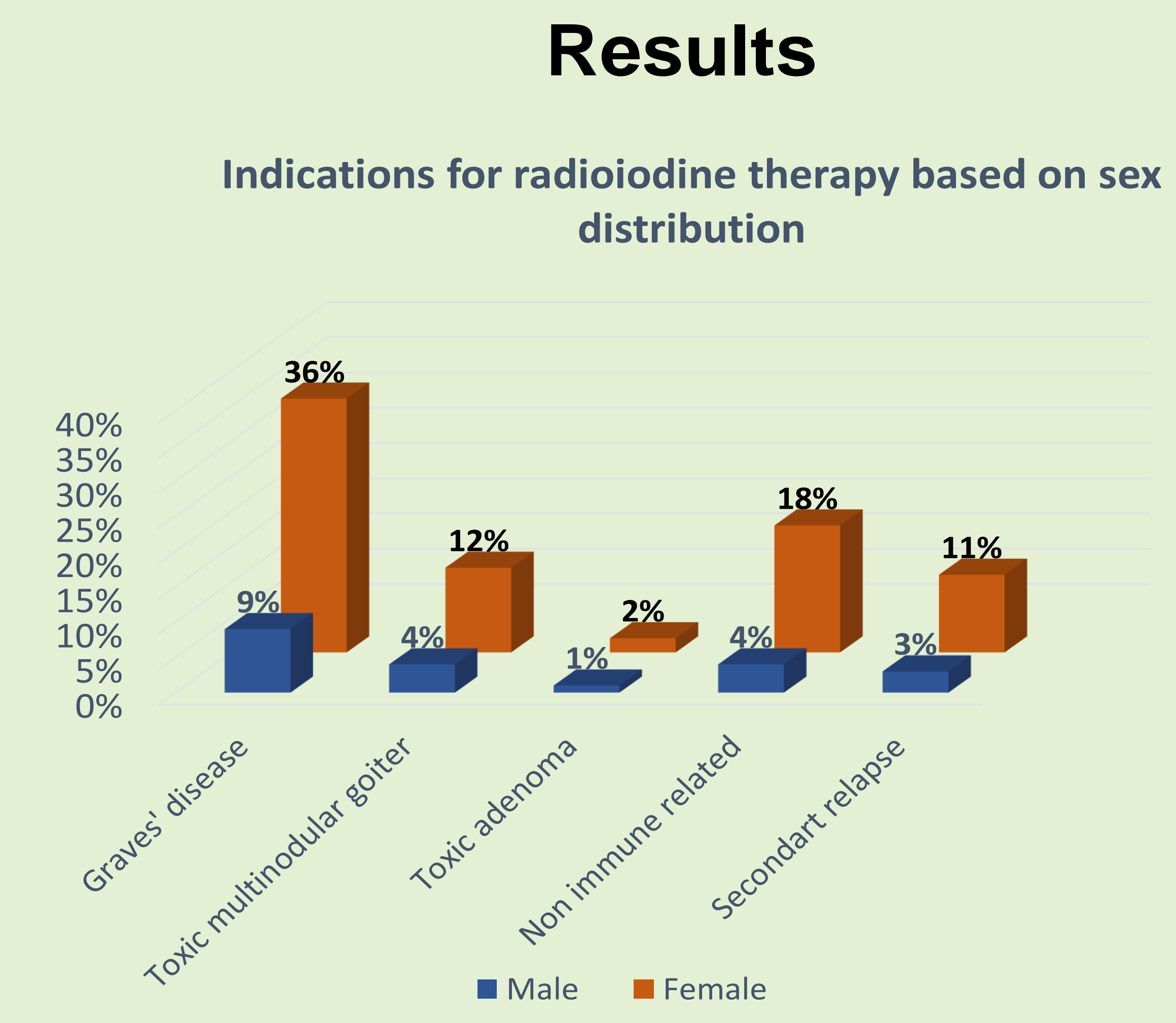

- Median radioiodine dose used for Graves' disease and MNG patients were $534 \mathrm{MBq}$ (range 530-560 MBq) to render euthyroid or hypothyroidism.

- Two third (78\%) had their thyroid function tested on the day of RAI treatment.

Outcome of radioiodine therapy in all patient groups

\section{Outcome of radioiodine therapy by} pie chart

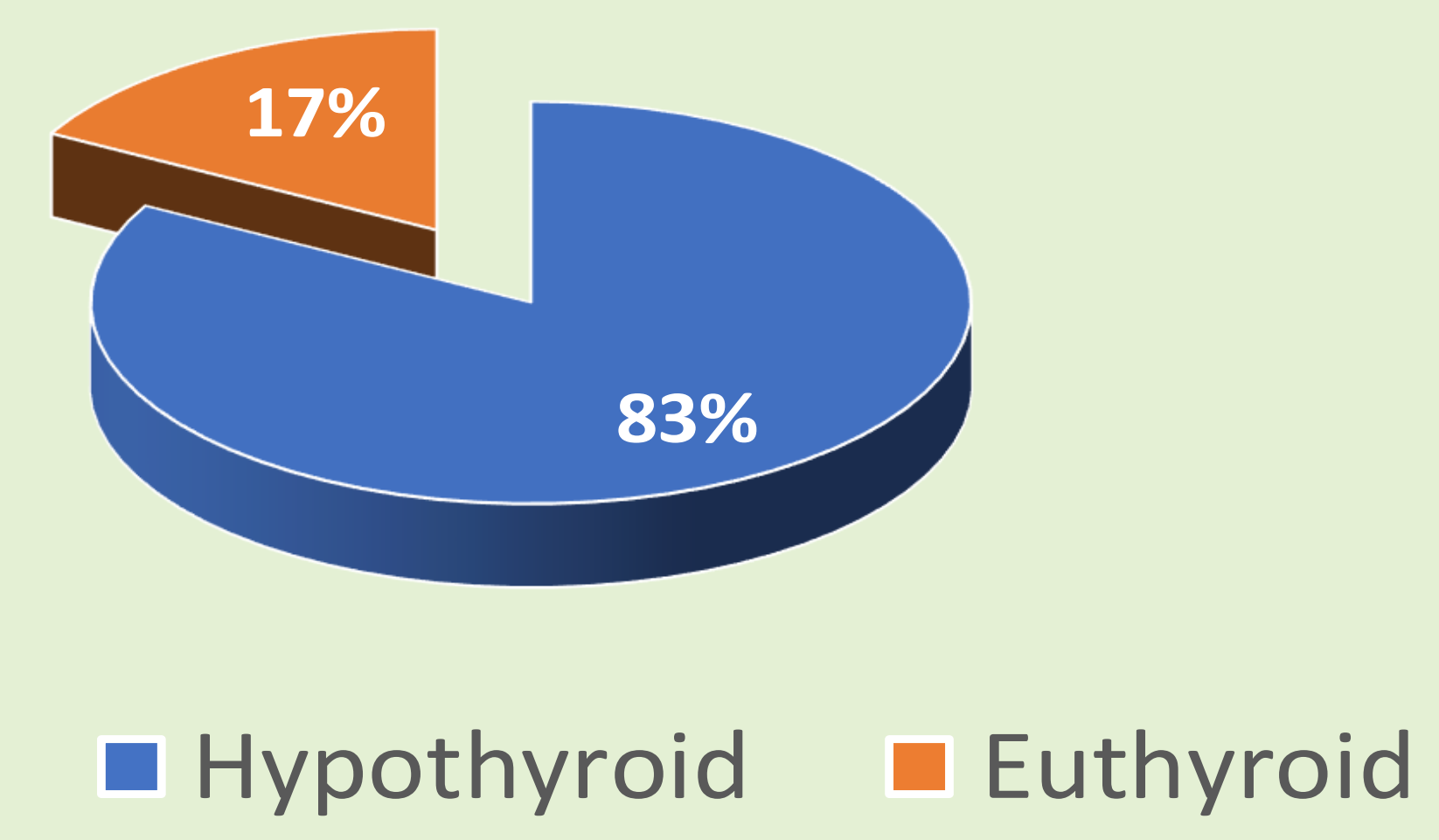

- The median duration for the first follow up was 8 weeks (range 6- 9 weeks).

Comparison of thyroid function tests of those patients during follow up

\begin{tabular}{|c|c|c|c|}
\hline $\begin{array}{c}\text { Follow - } \\
\text { up }\end{array}$ & $\begin{array}{c}\text { Number of } \\
\text { patients (\%) }\end{array}$ & $\begin{array}{c}\text { Mean Free T4 } \\
\text { ug/dl (range) }\end{array}$ & $\begin{array}{c}\text { Mean TSH } \\
\text { mIU/L } \\
\text { (range) }\end{array}$ \\
\hline 8 weeks & 81 & $8.78(0.21-37)$ & $\begin{array}{c}3.08(<0.05 \\
-68.43)\end{array}$ \\
\hline 6 months & 85 & $\begin{array}{c}6.79(2.1- \\
36)\end{array}$ & $\begin{array}{c}12.33(<0.05- \\
95.82)\end{array}$ \\
\hline 12 months & 62 & $\begin{array}{c}2.89(3.87- \\
24)\end{array}$ & $\begin{array}{c}5.38(<0.05- \\
104.25)\end{array}$ \\
\hline
\end{tabular}

Comparison of thyroid function tests of those patients during follow up

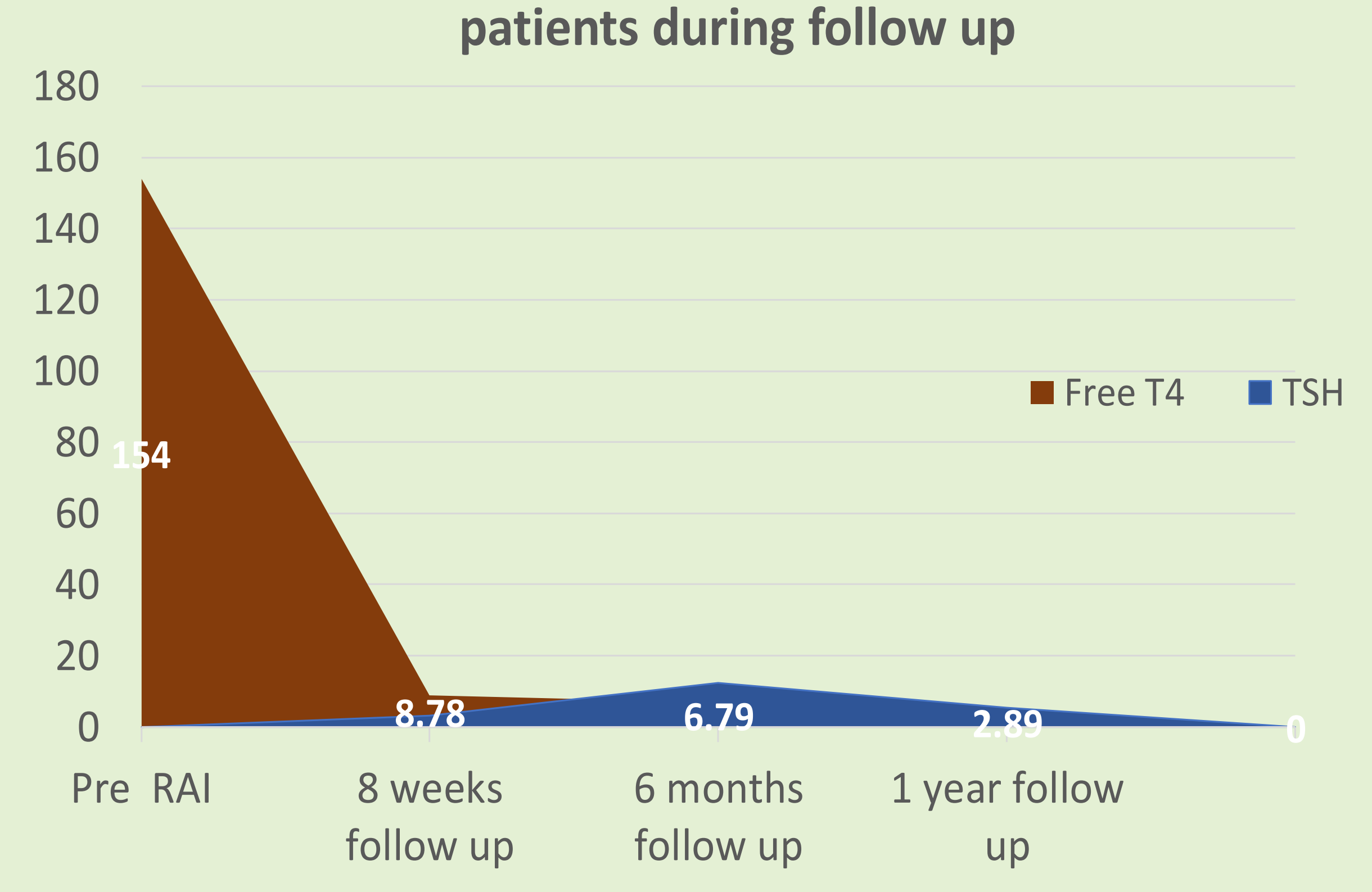

- The median duration for developing post radioiodine hypothyroidism was 10 weeks (range 6-34 weeks).

- Graves' hyperthyroid patients (50\%) had a higher incidence of developing post radioiodine hypothyroidism than MNG patients (34\%).

- Sixteen patients had severe biochemical disease with free T4 $>70 \mathrm{pmol} / \mathrm{L}$ at the time of diagnosis, and the majority who required a second dose of radioiodine after six months were men.

\section{Conclusion}

- Our audit data has shown the effectiveness of radioiodine therapy in virtually all hyperthyroid patients, especially Graves' and toxic MNG, by demonstrating a significant success rate.

- Hypothyroidism is an unavoidable phenomenon, but at the same time, many patients achieve euthyroid for a long term with fixed sufficient dose of radioiodine.

- Our study suggested that the current integral approach in managing individual hyperthyroid patients to be maintained while facilitating close collaboration with general practitioners to ensure their long term standardised followup and quality of care.

\section{References}

Radioiodine in the management of benign thyroid disease clinical guideline ( 2007)

2. Oxford Handbook of endocrinology and Diabetes, Edited by Katharine Owen, Edited by John Wass

3. Comparative effectiveness therapies of Graves Hyperthyroidism J Clin Endocrinol Metab 2013 Sep; 98(9): 3671-3677 ( 2013) 